\title{
Lenguajes dinámicos reales
}

Hace un tiempo atrás recibimos una invitación de universidad pública para darnos una conferencia sobre nuestras investigaciones científicas en la comunicación humana, específicamente en un de sus componentes más importantes y usado, en el día a día y en sus quehaceres, por sus productores: ser humano hablante mujer y ser humano hablante hombre, como lo es el componente sonoro o hablado, complementado con su registro prolongado en la línea del tiempo, como lo es la imagen visual, imagen escrita, habla escrita o escritura. Direccionado a través de las Lenguas Dinámicas Reales o Hablas Dinámicas Reales: Lengua Dinámica Uiraka (Colombia) y Lengua Dinámica Umonani (Brasil) dentro del marco teórico de la Lingüística Diversificada, LINDI o Teoría Hablaica. Siendo ese el tema a ser abordado durante dicha conferencia, lo centralizamos dentro del título: LENGUAJES DINAMICOS REALES.

La conferencia fue procesalmente desarrollada y su exposición fue orientada mediante el método interactivo, haciendo del expositor y de los participantes interactuar en la materia recíprocamente até el punto de no se discernir entre las partes, precisamente, por su dinamismo fuera de los patrones habituales. Sin embargo, este procedimiento contribuyo a detectar lo inesperado, participantes que no pertenecían al área señalada, que habianse incorporado en función, necesariamente, del mencionado título de la respectiva conferencia. Por lo tanto, teníamos participantes pertenecientes al área de la computación, informática, sistemas, programación, ingeniería de sistemas e ingeniería eléctrica. Eso nos llevó a concluir que el título de la mencionada conferencia no era lo esperado, no era preciso y si impreciso porque cargaba más una carga significativa, diferente a la carga del lenguaje hablado o escrito usado en la comunicación humana de una sociedad escolarizada y que hacia merecer su título. Cargando y sumando la misma marca de frases, muchas de ellas usadas en el cotidiano del contexto de las ventas, tales como: REGALAME EL NUMERO, DIGA PAPÁ, SÍ MAMÁ, DIGA MAMI, CORAZONCITO. Significando lo mismo que: DAME EL NUMERO DEL TELEFONO, A LA ORDEN SEÑOR, A LA ORDEN JOVEN, A LA ORDEN SEÑORA, A LA ORDEN SEÑORITA. Eso nos demuestra la limitante de los hablantes de la Lengua Castellana Oficial de Colombia tanto no uso cotidiano, cultural, empresarial, tecnológico, deportivo, científico, industrial, comercial, enseño y extensión. En función de las diferentes cargas significativas que pueden tener una palabra o una frase estableciéndose un sinnúmero de cargas significativas para la misma palabra o frase sonora, lo que determina desde ese punto, variedades de lenguas dentro de la misma lengua oficial castellana de Colombia. Demostrándonos que todo eso obedece a caprichos, poderes, mandatos, intereses de sectores minoritarios de la población hablante dominante de la mencionada lengua. Eso sin hablar en forma interdisciplinar de las carreras en su semejanza de contenido de la computación, con nombres de carreras diferente, tales como: sistemas, sistema de la información, ingeniería de sistemas, informática, programación, ingeniería eléctrica cuya fundamentación es la computación, la programación en cada una ellas. Esto nos demuestra por lo tanto, aspecto diferente a lo que dicen nuestros auto incumbidos poseedores del conocimiento y porque no, de la verdad. Que una lengua cambia en función de movimientos masivos de la población hablante. Cuando lo que estamos evidenciando es que esos cambios suceden también, a través de grupos minoritarios hablantes dominantes y en algunas de las veces mucho más rápido de las evidencias registradas. Como hemos notado, muchos de los cambios en la Lengua Castellana oficial de Colombia suceden en la carga significativa ya que la carga sonora continua la misma y lo que es más la imagen sonora puede cambiar pero la imagen escrita o la escritura continua a ser la misma. Esta evidencia hace que para diferencia y estudio, la Teoría de La Lingüística Diversificada, LINDI o Teoría Hablaica, denomine La Lengua Castellana Oficial de Colombia,

1 - Para muchos esta denominación puede parecer un poco extraña, porque por información desde la escuela nos hemos acostumbrado a pensar y a decir que el país es monolingüe, pero no es así. Y por la constitución nacional, las lenguas habladas dela población hablante de esos territorios es lengua oficial, con el mismo estatus de los hablantes de la lengua castellana oficial. Por otro lado, la mención de los hablantes de la Lengua Wayú es hecha exclusivamente para manifestar su existencia, porque dados de su dinamismo no los tenemos con precisión, partimos de la hipótesis de que es una Lengua Oficial Estática en función de que muchos estudiosos de la lengua clasifican y la estructuran siempre en función de la lengua gubernamental hablada y escrita. Lo que no debe ser hecho más. 
LENGUA ESTÁTICA OFICIAL, LENESO Lengua Castellana Estática Oficial de Colombia o LENESO, porque se conserva la estaticidad de la Lengua a través de la imagen visual, lengua escrita o escritura, independiente del dinamismo de la imagen sonora o lengua hablada. En esa línea obedecen las lenguas occidentales oficiales, tales como: La Lengua Portuguesa Oficial del Brasil, La Lengua Wayú Oficial ${ }^{1}$ de La Guajira, La Lengua Francesa Oficial, La Lengua Castellana Oficial, La Lengua Huitoto Oficial $^{2}$ del Amazonas, La Lengua Portuguesa Oficial, La Lengua Palenquera Oficial de Palenque ${ }^{3}$ Bolívar, La Lengua Guaraní Oficial del Paraguay, La Lengua Ticuna Oficial ${ }^{4}$ del Amazonas, La Lengua Guambiana Oficial del Cauca y del Huila ${ }^{5}$. La Lengua Papiamento Oficial del Curazao, La Lengua Inglesa Oficial, etc.

Ante esa problemática lingüística evidente de la Lengua Castellana Estática Oficial de Colombia, LENESO, desde hace 20 años hemos solucionado, científicamente, la problemática Lingüística de Colombia con su lengua oficial de comunicación al construirnos desde el marco Teórico de La Lingüística Diversificada, LINDI o Teoría Hablaica, La Lengua Dinámica Real o El Habla Dinámica Real, y no solo para el país, sino también, para el Brasil, que está con la misma problemática. De esa forma, fueron construidas Las Lenguas Dinámicas Reales o Las Hablas Dinámicas Reales: Uiraka (Colombia) y Umonani (Brasil). Que durante este proceso temporal y de estudio han pasado por tres etapas: Como lenguas ideales e experimentales, como lenguas dinámicas reales y en exposición y discusión como lenguas dinámicas equilibrio, en la construcción de hablas dinámicas reales equilibrio a partir de la inclusión de sus productores hablantes, ser humano hablante mujer, ser humano hablante hombre. Siendo que ese equilibrio está en estudio ante su comunidad hablante en las dos formas: 1. Incluyendo todas las partículas de femineidad en la frase para hablante mujer e inclusión de todas las partículas de masculinidad en la frase para hablante hombre, un ejemplo puede ser apreciado en la locución del poema (4.) SIN KUBRAR LAS PESONAS. 2. Incluyendo solo nombres femeninos del hablante mujer e inclusión solo de los nombres masculinos del hablante hombre. Este procedimiento lo estamos dando a conocer porque el intuito es debatir las dos formas, visto que como se parte de la costumbre de una lengua estática oficial con grande dosis de elementos masculinos y de elementos no masculinos ni femeninos, al hablarnos o escucharnos una palabra o una frase en fala dinámica real que antes tenía su línea masculina en femenina o que antes no era ni femenina ni masculina en frase masculina, causa a sensación de no ser adecuado en función de la costumbre anterior. Por lo tanto, sus hablantes deben estar conscientes de lo que es una lengua dinámica equilibrio o habla dinámica equilibrio como la pretendida por los hablantes de lenguas dinámicas reales, que es la inclusión de la hablante mujer y del hablante hombre en igual proporción, como es concebido en La Lengua Dinámica Real Uiraka.

Por consiguiente, Las Lenguas Dinámicas Reales sobre el marco Teórico de La Lingüística Diversificada, LINDI o Teoría Hablaica están listas para ser usadas o para substituir, si es esa la disponibilidad, Las Lenguas Estáticas Oficiales, y ser habladas por la población hablante de los respectivos países. De esta forma, y entrando de nuevo específicamente en nuestro caso, por sus facilidades de comunicación, inclusión, aprendizaje, adquisición, enseño y usos en la vida cotidiana y en las áreas del conocimiento, bien como, en la esfera social, cultural, empresarial, industrial, deportiva, tecnológica y científica, La Lengua Dinámica Real Uiraka de una comunidad hablante, presentase como lo más avanzado del mundo de la ciencia de la comunicación humana, por constituirse por la comunicación directa (Habla cotidiana, habla profesional, habla científica, etc.) y por la comunicación indirecta (Habla de chiste, literatura, cine, cultura, etc.). Por su aspecto intrínsecamente y esencialmente comunicativo: sea vía imagen sonora o hablada o vía imagen visual o escritura). Por la precisión de sus enunciados o expresiones sea na línea de la imagen hablada o de la imagen escrita. Por su representación visual ser dependiente total de la imagen sonora o imagen hablada. Por ser su imagen visual dinámica al cambiar junto con el dinamismo de la lengua hablada. De ese modo, la lengua dinámica en cuestión, se define no marco Teórico de La Lingüística Diversificada, LINDI o Teoría Hablaica como variante de la población hablante de la Lengua Castellana Hablada de Colombia Contemporánea, que desde su creación 1995, fue sistemáticamente diferenciándose, de La Lengua Castellana Estática Oficial de Colombia, a partir de su

2 - De igual manera, es una lengua oficial en el Amazonas y en su capital Leticia. Por otro lado, la mención de los hablantes de la Lengua Huitoto es hecha exclusivamente para manifestar su existencia, porque dados de su dinamismo no los tenemos con precisión, partimos de la hipótesis de que es una Lengua Oficial Estática en función de que muchos estudiosos de la lengua clasifican y la estructuran siempre en función de la lengua gubernamental hablada y escrita. Lo que no debe ser hecho más.

3 - Lengua oficial en la ciudad de Palenque, Bolivar a $51 \mathrm{~km}$ de Cartagena. Por otro lado, la mención de los hablantes de la Lengua Palenquera es hecha exclusivamente para manifestar su existencia, porque dados de su dinamismo no los tenemos con precisión, partimos de la hipótesis de que es una Lengua Oficial Estática en función de que muchos estudiosos de la lengua clasifican y la estructuran siempre en función de la lengua gubernamental hablada y escrita. Lo que no debe ser hecho más.

4 - Es lengua oficial en el territorio del Amazonas y en su capital Leticia en función de sus poblaciones hablantes de la Lengua Ticuna, gozando del mismo estatus que los hablantes de la Lengua Castellana Oficial reconocido y garantizado por la constitución nacional. Por otro lado, la mención de los hablantes de la Lengua Ticuna es hecha exclusivamente para manifestar su existencia, porque dados de su dinamismo no los tenemos con precisión, partimos de la hipótesis de que es una Lengua Oficial Estática en función de que muchos estudiosos de la lengua clasifican y la estructuran siempre en función de la lengua gubernamental hablada y escrita. Lo que no debe ser hecho más.

5 - Es lengua oficial en territorios del Cauca y del Huila, en función de sus poblaciones hablantes de la Lengua Guambiana, gozando del mismo estatus que los hablantes de la Lengua Castellana Oficial reconocido y garantizado por la constitución nacional. Por otro lado, la mención de los hablantes de la Lengua Guambiana es hecha exclusivamente para manifestar su existencia, porque dados de su dinamismo no los tenemos. De esta forma, los remito a vuestro Profesor Luis Humberto Alvarado Castañeda para que nos ilustre con su conocimiento desde la época de su investigación del sistema fonológico guambiano. 
misma constitución, iniciándose por los sonidos de la cadena hablada, siendo cada uno de los sonidos fonemáticos representados por su correspondiente letra o grafema, diferenciándose por su dinamismo y en el día de hoy por su dinamismo equilibrio al incluir en su habla los dos productores únicos del habla humana, como lo son, el ser humano mujer y el ser humano hombre en todas sus frases o en todos sus enunciados, donde cada uno de ellos y ellas participan o juntamente ellos y ellas participan como hablantes equitativos (en igualdad de condiciones hablaicas) de la Lengua Dinámica Equilibrio Uiraka o Habla Dinámica Equilibrio Uiraka. Constituyese diferente a partir de su concepción, al estar cristalizada única y exclusivamente por la pronunciación del habla de La Comunidad Hablante Uiraka en la generación de sus reglas en la emisión de sus frases o alocuciones. Por la generación de reglas siempre dentro de la lógica e idiosincrasia de la comunidad hablante uiraka. Por la generación de una habla uiraka dinámica independiente y americana a partir de sus hablantes. Por su concepción científica, el habla dinámica uiraka es comprobada de métodos científicos siempre en la ambientación de la comunidad hablante uiraka. Por su concepción calendárica, ya es regida por el calendario dinarroa no existiendo días sino vueltas. Por su concepción territorial: Del punto de vista del nombre, uiraka, debe poseer un nombre autónomo o generado en la región donde se habla. Por la extensión geográfica. Científicamente una comunidad hablante uiraka extiendese de 5 a $10 \mathrm{~km}$ a la redonda después de ese límite puedese presentar otra comunidad hablante, así en los más de $1.141 .000 \mathrm{~km} 2$ científicamente deben manifestarse más grupos biológicos hablantes, por lo tanto, mayor número de hablas (lenguas) de comunicación humana, de esa forma, cada región, pueblo, ciudad, departamento puede desarrollar su lengua humana de comunicación; a no ser que tengamos una ciencia Hablaica o ciencia lingüística con fines políticos partidarios, donde podemos tener una lengua estática oficial para toda la nación. De ese modo, la ciencia lingüística con fines políticos partidarios, dejaría de ser ciencia y sí técnica, tecnología, norma o regla, ya que la ciencia Hablaica es dinámica como lo es el habla humana, e a ciencia lingüística con fines políticos partidarios se estatiliza, de estaticidad o de estático, en favor de lo que incumbe para o sector de la comunidad hablante dirigencial en sus dirigidos hablantes. Ese hecho trae como consecuencia inmediata el estudio, para nuestro caso, los estudios lingüísticos, cuyos departamentos no consiguen generar y practicar en sus alumnas y alumnos ciencia lingüística en virtud de marcos teóricos sostenidos por el peso de supergalardonados y de esa forma, nuestros profesores y futuros profesores continúan dando saltos y saltos para esquivar, moldar, persuadir, obligar, convencer o alumno a aceptar, a no evadirse de la clase y entender y comprender su lengua, su lengua materna, su lengua nativa, nuestra lengua castellana estática oficial, que ni siquiera ha sido nacionalizada a pesar del cacareado grito, a pesar de las evidencias científicas que demuestran su diferencia, incluso de
Neiva a San Agustín, ahora si la estudiamos en las otras áreas geográficas del país, en los países vecinos o en ultramar van a decir los considerados poseídos de valor científico lingüístico ¡Que en parte puede ser cierto! Pero que falta todavía sustentación científica en el autor. Dentro de esta orden de acontecimientos de la comunicación humana, específicamente de las lenguas dinámicas reales, en el marco teórico de la Teoría Habláica, TEHA o Teoría de la Lingüística Diversificada, LINDI, pueden se desarrollar cursos, seminarios, talleres, debates, conferencias, dramatización, traducción, musicalización, investigaciones de las lenguas dinámicas de la región del Huila y del Huila Grande, contornando con el habla dinámica real: Uiraka (Colombia) y lenguas nativas, no solo en la vía del aprendizaje, de la enseñanza, de la investigación, de la dramatización y danza sino como vehículos, también de comunicación del Huila Grande desde su capital Neiva, con cuerpo de traductores bilingües, trilingües y cuerpos dirigénciales también, autóctonos. Ya con referencia al título de esta obra, Lenguajes Dinámicos Reales, escrito en Lengua Estática Oficial Castellana, es usado con la misma carga significativa de Lenguas Dinámicas Reales o Hablas Dinámicas Reales, como si fuese escrito en lenguas dinámicas reales, para nuestro caso en Lengua Dinámica Real Uiraka. De esa forma, hemos observado a través del desarrollo del tema y de la confusión generalizada que fue descrita, que el titulo con la palabra lenguaje, en la Lengua Estática Oficial Castellana no es concreto. Siendo de igual manera, presentada originalmente su carga significativa diferencial entre la carga significativa de lenguaje y lengua. No obstante su uso, y con el venir de otras disciplinas, como la computación, la comunicación, la informática, etc. fue transportada su carga significativa para estas disciplinas sin la distinción que es lenguaje humano o que es lenguaje artificial, sino como lenguaje. Además hay otro gravante, los hablantes de Lengua Castellana Oficial han generado la distinción entre la carga significativa de LENGUAJE y LENGUA, pero en la realidad es confusa esa distinción, cayéndose en la mayoría de sus usuarios hablantes, en el uso de estas palabras como sinónimas. Esa imprecisión significativa no sucede haciendo uso, los usuarios hablantes de Lenguas Dinámicas Reales, para nuestro caso que estamos tratando, en Lengua Dinámica Real Uiraka (Habla Dinámica Real Uiraka), para este efecto es usado solamente la palabra HABLA, como un dos componentes más importantes da comunicación humana. Conexiones de comunicación diferentes al ser humano, como por ejemplo en la computación es hecha siempre la carga significativa para este fin, a través de la comunicación artificial que es ejecutada por una máquina. De esa forma hay la distinción precisa para la situación de la comunicación humana y de la comunicación artificial a través del enunciado sonoro y visual que sigue este último, siempre la sonoridad del habla dinámica real uiraka. Siendo por lo tanto, más precisa en su carga significativa, reduciendo el grado de ambigüedad sustancialmente. 


\section{Referencias}

Bukurá Padilla, Serena. GABO, 73 AÑOS PRESO DE LAS REGLAS ARTIFICIALES DE LA LENGUA ESTATICA OFICIAL CASTELLANA. Revista Cacumen, Facultad de Educación de la UniCordoba, Montería, 2007

Galindo, Jairo. TEORIA FALAICA OU TEORIA LINGUÍSTICA DIVERSIFICADA NA DESCRICÃO DE LÍNGUAS DINÂMICAS REAIS. Tese livre docência. Săo Paulo, Produçôes Uiraumona, inédita.

Nuestra Lengua, ja, ja: Libreto para teatro y para guion de cine. $1^{\text {}}$ ediçẩo, São Paulo, Produções Uiraumona, 1999.

A Língua Ideal e La Lengua Ideal: Línguas Experimentais: Língua Umonani (Brasîl) e Lengua Uiraka (Colômbia). $1^{\circ}$ ediçẫo, Sâo Paulo, Producôes Uiraumona, 1997.

. Revista EL BUO. Ilustraciones, plurilingüismo: Lenguas aborígenes de la región (Ticuna e Huitoto), con Lenguas Castellana, Portuguesa, Inglesa e Francesa. Disciplina Lengua Castellana, Colegio Nacional Nocturno Alvernia, Leticia, 1991

Andrades Campana, Benito Alberto. CONHECIMENTO, INCLUSÃO E PARTICIPACÃO DOS FALANTES NATIVOS DA LIINGUA PALENQUERA NO PROUTAGUAIBA.

http://prounitaguaiba.pro.br/CoinL.INPAprouta.htm Sâo Paulo, 2007. Acessado em 20 de fevereiro de 2015.

Galindo, Jairo. Inclusẫo do gênero feminino com a concordância entre as partes das línguas naturais humanas, nas línguas dinâmicas reais. Mesa redonda online 2012: em homenagem a mulher!

http://www.prounitaguaiba.pro.br/resumosEMROHM2012.html Sảo Paulo, 2012. Acessado em 18 de janeiro de 2015.

Gimaraus Jizouzu Felisianu. PLAZA MULIERA SIN BLUSA. Poema: SIN KOBRAR AS BIKAS.

https://www.youtube.com/watch?v=iv7ti5cBoC8 Febraeska febraesko. São Paulo, 22 de abril de 2013

Isaso Palomino, Benko Seijankuo. PLASA MUJERA SIN BLUSA. Poema SIN KUBRAR LAS PESONAS.

https://www.youtube.com/watch?v=j5E6oBkhVkg Fekoesko Fekoeska. Puritol, 03 de marzo de 2013. 